\title{
O USO DA MADEIRA EM UMA SERRARIA DO SÉCULO XIX EM SANTA CATARINA ${ }^{1}$
}

\author{
JOÃO CARLOS FERREIRA DE MELO JÚNIOR²
}

\section{RESUMO}

Com o intuito de contribuir com a ampliação de informações sobre o uso de madeiras históricas usadas em bens patrimoniais de Santa Catarina, o presente estudo identificou as madeiras históricas se uma serraria do século XX. Foram identificadas cinco espécies de madeira com distribuição na Mata Atlântica, como a peroba (Aspidospema australe), o ariribá (Centrolobium microchaete), marmeleiro (Dalbergia brasiliensis), o ipê (Handroanthus chrysotrichus) e a canela (Ocotea porosa). Tais espécies tem sido exploradas pelas serrarias desde o período colonial e retratam aspectos da relação sociedade x natureza no tocante à extração de madeiras e conservação das florestas do país.

Palavras-chave: patrimônio cultural, cultura material, edificações históricas de Santa Catarina, madeiras históricas, anatomia da madeira.

\section{ABSTRACT}

[The use of wood in a nineteenth century sawmill in the State of Santa Catarina (Brazil)].

With the purpose of contributing to the expansion of information about the use of historical woods in patrimonial objects of Santa Catarina, the present study identified the historical woods of a sawmill from the twentieth century. Five wood species from the Atlantic Forest were identified, such as peroba (Aspidospema australe), ariribá (Centrolobium microchaete), marmeleiro (Dalbergia brasiliensis), ipê (Handroanthus chrysotrichus) and canela (Ocotea porosa). These species have been exploited by sawmills since the colonial period and portray aspects of the society $\mathrm{x}$ nature relationship regarding the extraction of wood and conservation of the country's forests.

Keywords: cultural heritage, material culture, historic buildings of Santa Catarina, historical woods, wood anatomy

\section{INTRODUÇÃO}

A relação homem x natureza é parte indissociável das expressões culturais e da produção do patrimônio cultural no Brasil. Reconhecidamente, grande parte dos objetos e bens culturais brasileiros resulta da apropriação dos recursos oferecidos pela natureza, sendo a madeira a matéria-prima de maior importância para o desenvolvimento das sociedades humanas no período histórico.

O período colonial no estado de Santa Catarina, sul do Brasil, foi marcado pelo intenso uso de recursos madeireiros provenientes das

1 Recebido em 09-12-2016 e aceito para publicação em 27-01-2017.

2 Biólogo, Doutor, Professor Titular do Departamento de Ciências Biológicas, Laboratório de Anatomia e Ecologia Vegetal, Universidade da Região de Joinville, Joinville, Santa Catarina, Brasil. joao.melo@ univille.br formações florestais da Mata Atlântica (Melo Júnior, 2012a). Os elevados estoques naturais de certas espécies de madeira assumiram posição de destaque no suprimento de matéria-prima que abasteceu, durante muitas décadas, o comércio madeireiro do sul do Brasil (Goularti Filho, 2002), sendo, por exemplo, a madeira do pinho (Araucaria angustifolia - Araucariaceae) largamente empregada em reparos de embarcações europeias desde a colonização do país (Hoff \& Simioni, 2004), bem como na construção de edifícios históricos em distintos períodos e de objetos domésticos do cotidiano colonial (Melo Júnior, 2012b; Melo Júnior \& Boeger, 2015).

$\mathrm{O}$ uso da madeira em estruturas construtivas de edificações históricas tem sido estudado no país sob diferentes enfoques, mas, de forma geral, permite perceber as relações de uso dos recursos naturais, o conhecimento tecnológico 
sobre as essências florestais, as técnicas, padrões arquiteturais e memórias de diversas sociedades humanas. Neste cenário, destacam-se os estudos realizados com igrejas jesuíticas e barrocas (Schulze-Hofer \& Marchiori, 2008, 2009a, 2009b; Marchiori \& Schulze-Hofer, 2009a, 2009b; Silva et al., 2010; Andreacci \& Melo Júnior, 2011), casarões, escolas e habitações coloniais (Abreu, 2010; Marchiori \& SchulzeHofer, 2010; Azevedo, 2014; Melo Júnior \& Boeger, 2015), fortes (Melo Júnior, no prelo) e engenhos (Terezo, 2004).

As madeireiras e as serrarias estão incluídas no conjunto de edificações históricas que retratam a exploração das florestas brasileiras. Registros históricos mostram que a exploração das madeiras do pinho e das canelas (Ocoeta sp. e Nectandra sp. - Lauraceae) perdurou até meados do século XX por serrarias instaladas no interior de Santa Catarina (Hoff \& Simioni, 2004). No município de Três Barras, instalou-se, em 1911, a maior serraria da América Latina - a Lumber -, para explorar as madeiras da região, dentre as quais o pinho, a imbuia, o cedro e a canela (Carvalho \& Nodari, 2008). Durante os quase 55 anos de funcionamento, esta e outras quase 200 serrarias instaladas em Santa Catarina e no Paraná abasteceram os mercados nacional e estrangeiro com a retirada de, aproximadamente, 8,5 milhões de toneladas de madeira de pinho (INP, 1948,1958,1968), a principal madeira exportada pelo Brasil (Hueck, 1972), o que contribuiu, significativamente, para a devastação da floresta de araucária (Carvalho \& Nodari, 2008).

O presente trabalho objetiva contribuir com a ampliação de informações sobre o uso de madeiras históricas usadas como matéria-prima na construção de uma serraria da década de 1950, a qual, apesar de ter contribuído para o esgotamento de muitas madeiras nos ambientes naturais, integra o patrimônio cultural de Santa Catarina e ajuda a aclarar alguns aspectos da relação sociedade x natureza.

\section{MATERIAL E MÉTODOS}

A construção histórica aqui investigada é uma serraria localizada na cidade de Joinville, região nordeste do estado de Santa Catarina (Figura 1). Pertenceu à família Kohn e funcionou de 1954 até 2000 . Em função da venda do terreno que a abrigava, foi doada para a Universidade da Região de Joinville, onde foi remontada para fins de preservação desta memória. Ela apresenta toda a estrutura arquitetural e o próprio maquinário confeccionado em madeira, e ocupa cerca de $180 \mathrm{~m}^{2}$ (Campos, 2008).

Amostras de madeira foram coletadas de todas as estruturas construtivas da serraria e também do maquinário. Destas amostras, foram confeccionados corpos de prova com dimensão de $2 \times 2 \times 2 \mathrm{~cm}$ para posterior cozimento em água glicerinada (Ferreirinha, 1958) e subsequente seccionamento em micrótomo de deslize, nos planos transversal, longitudinal tangencial e longitudinal radial (Kraus \& Arduin, 1997). Os cortes histológicos resultantes foram clarificados em hipoclorito de sódio $(\mathrm{NaClO})$, lavados em água destilada, corados com safrablau e desidratados em série etílica crescente (Kraus \& Arduin, 1997). Lâminas histológicas foram preparadas de acordo com a metodologia comum em anatomia da madeira (Johansen, 1940), montadas em resina sintética (Paiva et al., 2006) e depositadas na coleção de referência de madeiras históricas da Xiloteca JOIw, da Universidade da Região de Joinville (Melo Jr. et al., 2014).

As descrições anatômicas seguiram a terminologia proposta pelo IAWA Committee (IAWA, 1989). A identificação das espécies de madeira foi realizada por comparação com a coleção de referência de madeiras da flora atual da mesma xiloteca, bem como por consulta a obras de referência (Record \& Hess, 1943; Metcalfe \& Chalk, 1950; Détienne \& Jacquet, 1983; Mainieri \& Chimelo, 1989) e ao banco de dados Inside Wood (Wheeler, 2011). 


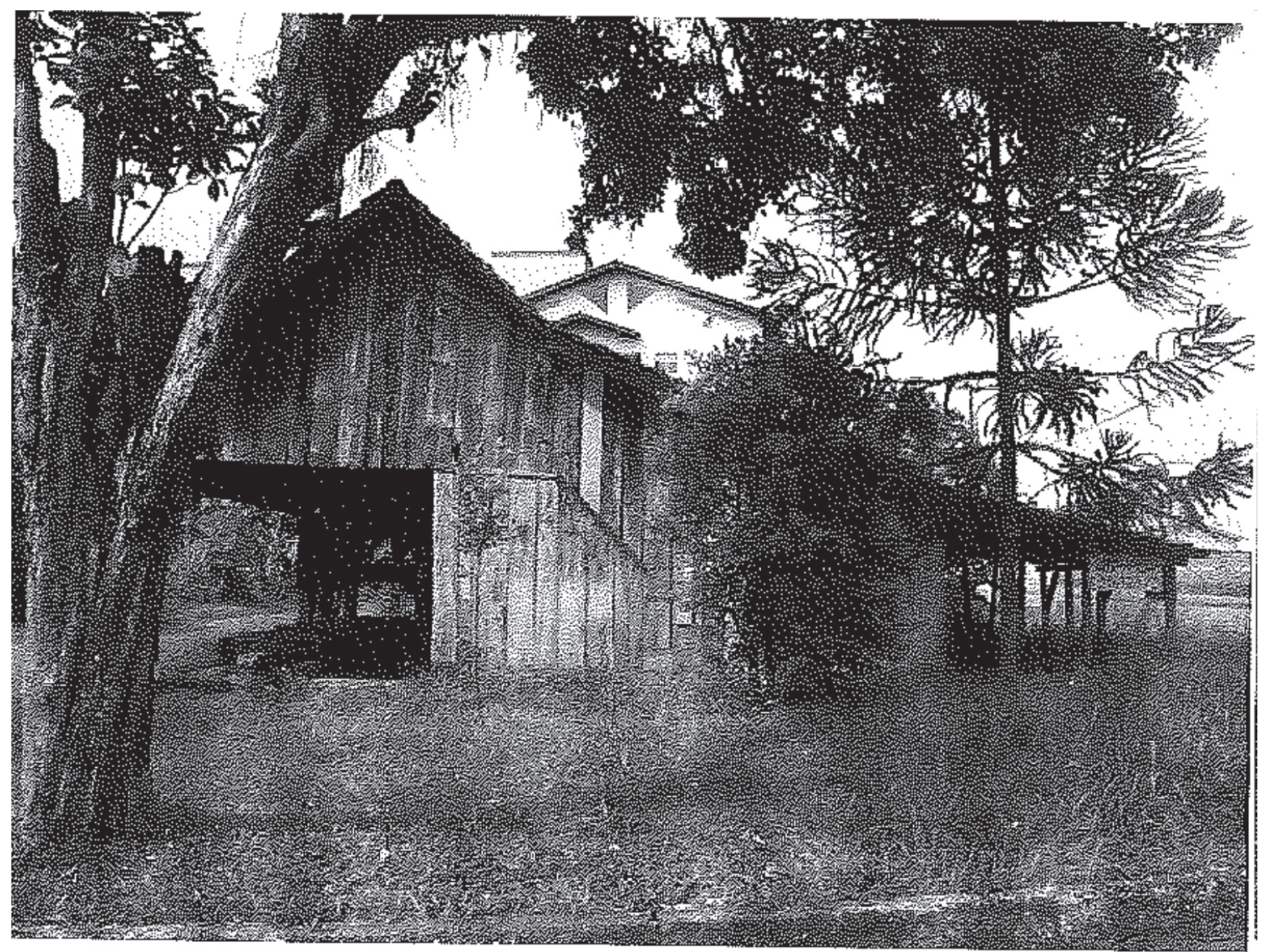

FIGURA 1. Serraria Kohn em sua montagem original, Joinville, Santa Catarina.

(Fonte: Campos, 2008).

\section{RESULTADOS}

Foram identificadas cinco espécies de madeira, pertencentes a quatro famílias botânicas: Aspidosperma australe Müll. Arg. (Apocynaceae, peroba), Centrolobium microchaete (Mart. ex Benth.) H.C.Lima (Fabaceae, ariribá), Dalbergia brasiliensis Vogel. (Fabaceae, marmeleiro), Handroanthus chrysotrichus (Mart. ex DC.) Mattos (Bignoniaceae, ipê) e Ocotea porosa (Nees \& Mart.) Barroso (Lauraceae, canela). A família mais representativa foi Fabaceae, com duas espécies de madeira. A Tabela 1 apresenta os principais caracteres de diagnose das madeiras identificadas.

As madeiras utilizadas com função estrutural na serraria foram: a canela, nos pilares; o ariribá, na estrutura do telhado; e a peroba, nas tábuas das paredes. O maquinário (serra) foi produzido com as madeiras de ipê e de marmeleiro (Figura 2).

\section{DISCUSSÃO}

As espécies identificadas pertencem a plantas de hábito arbóreo encontradas em florestas pluviais semideciduais, mista e de galeria, de domínio da Mata Atlântica, com registro de distribuição geográfica na região sul do país, sendo a peroba, o marmeleiro e o ipê encontrados nos três estados (Lohmann, 2015; Koch et al., 2015; Lima, 2015), e o ariribá e a canela restritas ao Paraná e Santa Catarina (Klitgaard, 2015; 
TABELA 1. Características anatômicas usadas na identificação das espécies de madeira da serraria Kohn, Joinville, Santa Catarina.

\begin{tabular}{|c|c|c|c|}
\hline $\begin{array}{c}\text { Espécie de } \\
\text { madeira }\end{array}$ & Seção Transversal & Seção Longitudinal tangencial & Seção Longitudinal radial \\
\hline $\begin{array}{l}\text { Aspidosperma } \\
\text { australe }\end{array}$ & $\begin{array}{l}\text { Camadas de crescimento distintas, demarcadas por } \\
\text { parênquima marginal em linha unisseriada. Porosidade } \\
\text { difusa. Vasos exclusivamente solitários. Diâmetro } \\
\text { tangencial de } 50-100 \mu \mathrm{m} \text {. Frequência de } 40-100 \\
\text { vasos } / \mathrm{mm}^{2} \text {. Parênquima axial apotraqueal difuso, } \\
\text { difuso em agregado e marginal em linhas unisseriadas. }\end{array}$ & $\begin{array}{l}\text { Fibras nã o septadas com paredes finas a } \\
\text { espessas. Séries parenquimáticas compostas } \\
\text { por } 2-4 \text { células. Raios unisseriados, } \\
\text { homogêneos, formado por células } \\
\text { procumbentes. }\end{array}$ & $\begin{array}{l}\text { Placa de perfuração simples. Pontoações } \\
\text { intervasculares alternas, guarnecidas e } \\
\text { diminutas. Pontoações radio-vasculares } \\
\text { similares às intervasculares. Cristais } \\
\text { prismáticos em células subdivididas do } \\
\text { parênquima axial. }\end{array}$ \\
\hline $\begin{array}{l}\text { Centrolobium } \\
\text { microchaete }\end{array}$ & $\begin{array}{l}\text { Camadas de crescimento distintas, demarcadas por } \\
\text { zona fibrosa. Porosidade difusa. Vasos solitários e } \\
\text { geminados. Di âmetro tangencial de } 100-200 \mu \mathrm{m} \text {. } \\
\text { Frequência } \leqslant 5 \text { vasos } / \mathrm{mm}^{2} \text {. Parênquima axial } \\
\text { paratraqueal aliforme losangular, confluente e em } \\
\text { faixas marginais. }\end{array}$ & $\begin{array}{l}\text { Fibras não septadas com paredes finas a } \\
\text { espessas. Séries parenquimáticas compostas } \\
\text { por } 2 \text { células. Raios predominantemente } \\
\text { unisseriados, homogêneos, formado por } \\
\text { células procumbentes. Raios e parênquima } \\
\text { axial estratificados. }\end{array}$ & $\begin{array}{l}\text { Placa de perfuração simples. Pontoações } \\
\text { intervasculares alternas, guarnecidas e } \\
\text { pequenas. Pontoações radio-vasculares } \\
\text { similares às intervasculares. Cristais } \\
\text { prismáticos em células subdivididas do } \\
\text { parênquima axial. }\end{array}$ \\
\hline $\begin{array}{l}\text { Dalbergia } \\
\text { brasiliensis }\end{array}$ & $\begin{array}{l}\text { Camadas de crescimento indistintas. Porosidade } \\
\text { difusa. Vasos solitários e múltiplos radiais } 2-3 \text {. } \\
\text { Diâmetro tangencial de } 100-200 \mu \mathrm{m} \text {. Frequência de 5- } \\
20 \text { vasos } / \mathrm{mm}^{2} \text {. Parênquima axial apotraqueal difuso e } \\
\text { difuso em agregado, paratraqueal escasso, } \\
\text { vasicêntrico, aliforme, confluente, unilateral e em } \\
\text { linhas com mais de três células de largura. Vasos } \\
\text { obstruídos por gomas ou outros depósitos. }\end{array}$ & $\begin{array}{l}\text { Fibras não septadas com paredes espessas. } \\
\text { Séries parenquimáticas compostas por } 2 \\
\text { células. Raios 1-2 seriados, heterogêneos, } \\
\text { com corpo formado por células procumbentes } \\
\text { e uma camada marginal de células eretas ou } \\
\text { quadradas. Raios, parênquima axial e vasos } \\
\text { estratificados. }\end{array}$ & $\begin{array}{l}\text { Placa de perfuração simples. Pontoações } \\
\text { intervasculares alternas, guarnecidas e } \\
\text { pequenas. Pontoações radio-vasculares } \\
\text { similares às intervasculares. Cristais } \\
\text { prismáticos em células subdivididas do } \\
\text { parênquima axial. }\end{array}$ \\
\hline $\begin{array}{l}\text { Handroanthus } \\
\text { chrysotrichus }\end{array}$ & $\begin{array}{l}\text { Camadas de crescimento distinta } \mathrm{s} \text {, demarcadas por } \\
\text { parênquima marginal em linha unisseriada. Porosidade } \\
\text { difusa. Vasos solitários e raros em múltiplos radiais. } \\
\text { Diâmetro tangencial de } 50-100 \mu \text { m. Frequência de } 5 \text { - } \\
20 \text { vasos } / \mathrm{mm}^{2} \text {. Parênquima axial paratraqueal } \\
\text { vasicêntrico, aliforme losangular, confluente, } \\
\text { unilateral e marginal em linhas unisseriadas. }\end{array}$ & $\begin{array}{l}\text { Fibras não septadas com paredes finas a } \\
\text { espessas. Séries parenquimáticas compostas } \\
\text { por 1-3 células. Raios bisseriados, } \\
\text { homogêneos, formados por células } \\
\text { procumbentes. Raios, parênquima axial e } \\
\text { vasos estratificados. }\end{array}$ & $\begin{array}{l}\text { Placa de perfuração simples. Pontoações } \\
\text { intervasculares alternas e grandes. Pontoaçõe } \\
\text { radio-vasculares similares às intervasculares. }\end{array}$ \\
\hline Ocotea porosa & $\begin{array}{l}\text { Camadas de crescimento distintas, demarcadas por } \\
\text { zona fibrosa. Porosidade difusa. Vasos solitários e } \\
\text { múltiplos radiais } 2-3 \text {. Diâmetro tangencial de } 50-100 \\
\mu \mathrm{m} \text {. Frequência de } 5-20 \text { vasos } / \mathrm{mm}^{2} \text {. Parênquima axial } \\
\text { paratraqueal aliforme losangular, confluente e em } \\
\text { faixas marginais. Vasos obstruídos por gomas ou } \\
\text { outros depósitos e tilos. }\end{array}$ & $\begin{array}{l}\text { Fibras septadas com paredes finas a espessas. } \\
\text { Séries parenquimáticas compostas por 3-4 } \\
\text { células. Raios 1-3 seriados, heterogêneos, } \\
\text { com corpo formado por células procumbentes } \\
\text { e uma camada marginal de células eretas ou } \\
\text { quadradas. }\end{array}$ & $\begin{array}{l}\text { Placa de perfuração simples. Pontoações } \\
\text { intervasculares alternas e grandes. Pontoações } \\
\text { radio-vasculares com bordas reduzidas a } \\
\text { aparentemente simples. Células oleíferas ou } \\
\text { mucilaginosas associadas ao parênquima } \\
\text { radial e axial. }\end{array}$ \\
\hline
\end{tabular}

Quinet et al., 2015). Destas espécies, apenas o marmeleiro (D. brasiliensis) é endêmica do Brasil (Lima, 2015).

Do ponto de vista do emprego tecnológico das madeiras, a peroba é citada como de boa qualidade na construção civil (Lorenzi, 2000; Paula \& Alves, 2007), o ariribá se destina ao fabrico de peças estruturais (Backes \& Irgang, 2004), o marmeleiro é comum em peças estruturais de construções rurais (Lorenzi, 2000), o ipê é próprio para obras externas, como tábuas para currais, e internas, como tábuas para assoalho (Lorenzi, 1992), e a canela é indicada tanto para estruturas internas, como forros, assoalhos, tacos e esquadrias, como externas, casos de moirões e dormentes (Lorenzi, 1992).

A atividade madeireira no estado de Santa Catarina acontece desde o início do processo de colonização, pela necessidade da construção de moradias, e os registros se estendem do século XVIII ao XIX. A disseminação dessa atividade deu-se pela instalação de pequenas ou grandes serrarias, que extraíam, beneficiavam e produziam derivados de madeira (Eduardo, 1974).

Durante o período colonial, houve certo controle da extração madeireira no país por parte da Coroa Portuguesa e, também, na Província de Santa Catarina, o corte de madeiras apenas ocorria com a autorização da Coroa e para atender a demanda dos arsenais da nação. Desta forma, até o final do século XIX não há registro da extração de madeiras no planalto de Santa Catarina, atividade esta que se expande com a colonização européia, a partir do estado do Rio Grande do Sul e adentra no centro-oeste de Santa Catarina (Eduardo, 1974). Na porção litorânea de Santa Catarina, a chegada dos imigrantes alemães e italianos levou à exploração madeireira, principalmente em função da necessidade da abertura de lavouras, o que culminou na abertura de muitas serrarias que aproveitavam os rios para o transporte de madeiras e das quedas d'água para mover as serras (Eduardo, 1974).

A exploração madeireira no sul do Brasil esteve condicionada às espécies de madeira exis- 


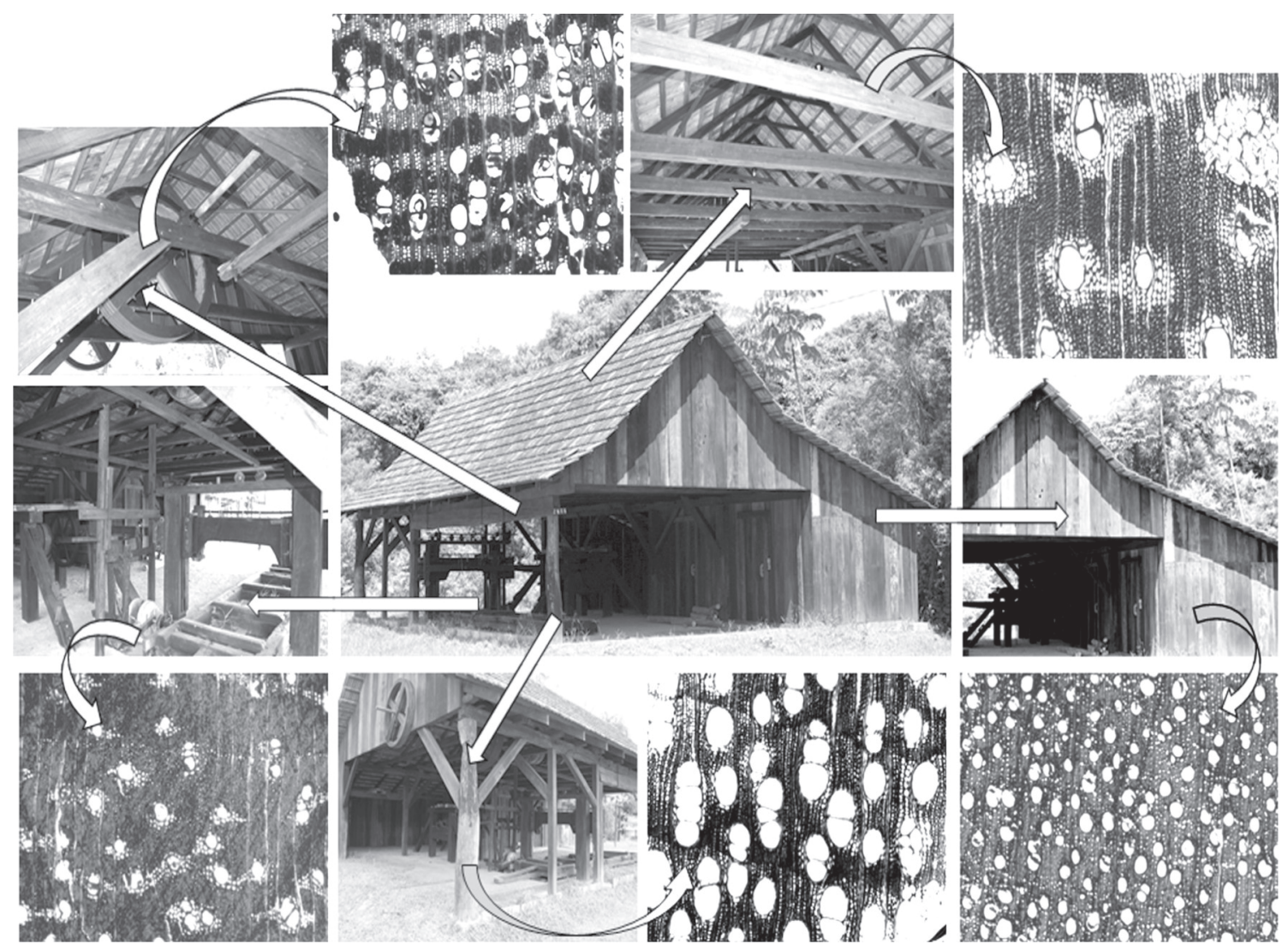

FIGURA 2. Anatomia das madeiras identificadas no maquinário e nas estruturas construtivas da serraria Kohn, Joinville, Santa Catarina. Legenda: Setas lineares indicam as ampliações das estruturas construtivas estudadas. Setas curvas indicam a anatomia da madeira identificada em secção transversal. A, vista geral da serraria Kohn. B, base do maquinário. C, haste de sustentação da serra. D, anatomia da madeira de Dalbergia brasiliensis. E, estrutura do telhado. F, anatomia da madeira de Centrolobium microchaete. G, tábuas usadas em paredes. H, anatomia da madeira de Aspidosperma australe. I, anatomia da madeira de Ocotea porosa. J, pilares de sustentação. K, anatomia da madeira de Handroanthus chrysotrichus.

tentes em cada local, sendo as primeiras serrarias destinadas à derrubada e corte das madeiras até a segunda metade do século XIX. As primeiras serrarias surgem pela necessidade de tábuas para a construção de casas e fins domésticos, além de limparem os terrenos para a agricultura (Cabral \& Cesco, 2008). Em função da elevada diversidade da flora na região litorânea de Santa Catarina, houve a instalação de numerosas serrarias de caráter rural, com produção de madeira de até $60 \mathrm{~m}^{3} / \mathrm{mês}$, mas com intenso registro de exportação de madeiras como cedro (Cedrella sp. - Meliaceae) e canela (Ocotea sp. - Lauraceae) (Eduardo, 1974). Segundo Ficker (2008), a primeira serraria de grande porte na porção litorânea de Santa Catarina foi instalada em Joinville, ao passo que, no planalto, a serraria Lumber se instalou por volta de 1914, com vistas à exploração da madeira de pinho (Carvalho \& Nodari, 2008).

No início do século XX, a exploração de madeiras no litoral catarinense foi intensa e sem qualquer preocupação com controle de produção e reflorestamento, sendo a produção de dormentes, ripas, tábuas, mourões, pernas de serra, sarrafos, assoalhos, vigas e peças para mobiliário os principais produtos do beneficiamento da madeira, que abastecia tanto a Argentina como as cidades do Rio de Janeiro e São Paulo (Eduardo, 1974).

Considerando o esgotamento dos recursos florestais, registra-se o deslocamento da ativi- 
dade madeireira do litoral para o planalto e, deste, para o extremo oeste do estado. Somente a partir de 1920, com a instalação de maquinários capazes de desdobrar grandes toras e o surgimento de meios de transporte adequados ao carregamento da madeira, a atividade madeireira tomou impulso (Cabral \& Cesco, 2008). As serrarias instaladas se dividiam em três categorias: as serrarias de pinho, que exploravam exclusivamente a madeira da Araucaria angustifolia (Araucariaceae); as de madeira de lei, que exploravam diferentes espécies; e as mistas, que exploravam tanto o pinho como madeiras de lei. Juntas, elas chegaram a somar 3.985 serrarias no estado de Santa Catarina, aproximadamente, até o início da década de 1970 (IBDF, 1972).

As espécies de madeira identificadas neste estudo sinalizam a necessidade da exploração de recursos florestais para a própria construção das serrarias. Conforme apontam Cabral \& Cesco (2008), a atividade madeireira foi muito presente no sul do país e, apesar de ter contribuído com o crescimento econômico da região, promoveu a devastação de sua base de sustentação (as florestas) e extinguiu a possibilidade de se ter uma auto-sustentabilidade econômico-ecológica (Andrade, 2003), uma vez que somente nas décadas de 1960 e 1970 surgiram leis de combate ao desmatamento, além de controle na exploração de certas espécies de madeira e de fiscalização das serrarias (Cabral \& Cesco, 2008). Por outro lado, a atividade desse tipo de indústria mostra a concepção de uso e apropriação da natureza, através do tempo histórico pela sociedade humana.

\section{REFERÊNCIAS BIBLIOGRÁFICAS}

ABREU, L.B. Ensaios não destrutivos para avaliação da integridade de elementos estruturais de madeiras em construções históricas. Tese (Doutorado em Ciência e Tecnologia da Madeira). Universidade Federal de Lavras, Lavras, MG, 2010.

ANDRADE, M.T.N. É preciso desmatar para crescer? Evidências empíricas para a região sul do Brasil. Monografia (Graduação em Economia), Universidade Federal do Rio de Janeiro, 2003.

ANDREACCI, F.; MELO JÚNIOR, J.C.F. Madeiras históricas do barroco mineiro: interfaces entre o patrimônio cultural material e a anatomia vegetal. Rodriguésia, Rio de Janeiro, v. 62 , p. 241-251, 2011.

BACKES, P.; IRGANG, B. Mata Atlântica: as árvores e a paisagem. Porto Alegre: Paisagem do Sul, 2004.

CABRAL, D.C.; CESCO, S. Notas para uma história da exploração madeireira na mata atlântica do sul-sudeste. Ambiente \& Sociedade, São Paulo, v. 11, n. 1, p. 33-48, 2008.

CAMPOS. J.P. Levantamento Cadastral: edificação referente à serraria situada à rua Dona Francisca, 2666, no bairro Saguaçu, cidade de Joinville. Relatório Técnico, 2008.

CARVALHO, M.M.X.; NODARI, E.S. 2008. A Lumber, o Contestado e a história do desmatamento da floresta de araucária (19111950). Disponível em: www.historiaambiental.org/a-lumber-o-contestado-e-ahistoria-do-desmatamento-da-floresta-dearaucaria1911-1950. Acesso em: janeiro de 2017.

DÉTIENNE, P.; JACQUET, P. Atlas d'identification des bois de l'Amazonie et des régions voisines. France: Centre Téchnique Forestier Tropical, 1983.

EDUARDO, R.P. A madeira em Santa Catarina (1930-1974). Dissertação (Mestrado em História). Universidade Federal do Paraná, Curitiba, PR, 1974.

FERREIRINHA, M.P. Elementos de anatomia de madeiras folhosas portuguesas. Memórias da Junta de Investigação do Ultramar, 1958.

FICKER, C. História de Joinville: crônicas da colônia Dona Francisca. Joinville: Letra d'água, 2008.

GOULARTE FILHO, A. Formação econômica de Santa Catarina. Florianópolis: Cidade Futura, 2002.

HOFF, D.N.; SIMIONI, F.J. O setor florestal na serra catarinense. Lages: Uniplac, 2004.

IAWA Committee. List of microscopic features for hardwood identification. IAWA Bulletin, v. 10, p. 220-332, 1989. 
IBDF - Instituto Brasileiro de Desenvolvimento Florestal. Anuário brasileiro de economia florestal - Relatórios dos delegados do IBDF em Santa Catarina, 1972.

INP - Instituto Nacional do Pinho. Quadros estatísticos. Anuário brasileiro de economia florestal, Rio de Janeiro, n.1, 1948.

INP - Instituto Nacional do Pinho. Quadros estatísticos. Anuário brasileiro de economia florestal, Rio de Janeiro, n.10, 1958.

INP - Instituto Nacional do Pinho. Quadros estatísticos. Anuário brasileiro de economia florestal, Rio de Janeiro, n.19, 1968.

JOHANSEN, D.A. Plant microtechnique. London: McGraw-Hill Company Inc., 1940.

KLITGAARD, B.B. Centrolobium in Lista de Espécies da Flora do Brasil. Jardim Botânico do Rio de Janeiro. 2015. Disponivel em: http:// floradobrasil.jbrj.gov.br/jabot/floradobrasil/ FB18256. Acesso em: janeiro de 2017.

KOCH, I.; RAPINI, A.; SIMÕES, A.O.; KINOSHITA, L.S.; SPINA, A.P.; CASTELLO, A.C.D. Apocynaceae in Lista de Espécies da Flora do Brasil. Jardim Botânico do Rio de Janeiro. 2015. Disponivel em: http:// floradobrasil.jbrj.gov.br/jabot/floradobrasil/ FB4521. Acesso em: janeiro de 2017.

KRAUS, J.E.; ARDUIN, M. Manual básico de métodos em morfologia vegetal. Seropédica: Edur, 1997.

LIMA, H.C. Dalbergia in Lista de Espécies da Flora do Brasil. Jardim Botânico do Rio de Janeiro. 2015. Disponível em: http://floradobrasil.jbrj.gov.br/jabot/floradobrasil/FB29592. Acesso em: janeiro de 2017.

LOHMANN, L.G. Bignoniaceae in Lista de Espécies da Flora do Brasil. Jardim Botânico do Rio de Janeiro. 2015. Disponível em: http://floradobrasil.jbrj.gov.br/jabot/floradobrasil/FB114078. Acesso em: janeiro de 2017.

LORENZI, H. Árvores brasileiras: manual de identificação e cultivo de plantas arbóreas nativas do Brasil. Nova Odessa: Plantarum, 1992.

LORENZI, H. Árvores brasileiras: manual de identificação e cultivo de plantas arbóreas nativas do Brasil. Nova Odessa: Plantarum, 2000.

MAINIERI, C.; CHIMELO, J.P. Fichas de características das madeiras brasileiras. São Paulo: IPT, 1989.
MARCHIORI, J.N.C.; SCHULZE-HOFER, C. O uso da madeira nas Reduções Jesuítico-Guarani do Rio Grande do Sul. VII - Viga do coro da igreja de São Miguel de Arcanjo. Balduinia, Santa Maria, v. 17, p. 29-33, 2009a.

MARCHIORI, J.N.C; SCHULZE-HOFER, C. O uso da madeira nas Reduções Jesuítico-Guarani do Rio Grande do Sul. 5 - Fragmento de madeira procedente de escavações arqueológicas no átrio da Igreja de São Lourenço. Balduinia, Santa Maria, v.16, p. 1-5, 2009b.

MARCHIORI, J.N.C.; SCHULZE-HOFER, C. O uso da madeira nas Reduções Jesuítico-Guarani do Rio Grande do Sul. 9 - Pilar do Colégio São Miguel Arcanjo. Balduinia, Santa Maria, v. 20, p. 5-9, 2010.

HUECK, K. As florestas da América do Sul: ecologia, composição e importância econômica. Brasília: Ed. da UnB, 1972.

MELO Jr., J.C.F.; BOEGER, M.R.T. The use of wood in cultural objects in 19th Century Southern Brazil. IAWA Journal, v. 36, n. 1, p. 98-116, 2015.

MELO Jr., J.C.F. Aspectos anatômicos de madeiras históricas do período colonial do nordeste de Santa Catarina: elementos para conservação do patrimônio cultural. Revista Confluências Culturais, v.1, p. 70-84, 2012a.

MELO Jr., J.C.F. Anatomia de madeiras históricas: um olhar biológico sobre o patrimônio cultural. Joinville: Univille, $2012 \mathrm{~b}$.

MELO Jr., J.C.F.; AMORIM, M.W.; SILVEIRA, E.R. A xiloteca (coleção Joinvillea - JOIw) da Universidade da Região de Joinville. Rodriguésia, v. 65, p. 1057-1060, 2014.

METCALFE, C.R.; CHALK, L. Anatomy of the Dicotyledons. Oxford: Claredon Press, 1950.

PAIVA, J.G.A.; FANK-de-CARVALHO, S.M.; MAGALHÃES, M.P.; GRACIANO-RIBEIRO, D. Verniz vitral incolor 500: uma alternativa de meio de montagem economicamente viável. Acta Botanica Brasilica, v. 20, p. 257-264, 2006.

PAULA, J.E.; ALVES, J.L.H. 897 Madeiras Nativas do Brasil: anatomia-dendrologia, dendrometria-produção-uso. Porto Alegre: Cinco Continentes, 2007.

QUINET, A.; BAITELLO, J.B.; MORAES, P.L.R. de; ASSIS, L.; ALVES, F.M. Lauraceae in Lista de Espécies da Flora do Brasil. Jardim Botânico do Rio de Janeiro. 2015. Disponivel em: http:// 
floradobrasil.jbrj.gov.br/jabot/floradobrasil/ FB8479. Acesso em: janeiro de 2017.

RECORD, S.J.; HESS, R.W. Timbers of New World. New Haven: Yale University Press, 1943.

SCHULZE-HOFER, C.; MARCHIORI, J.N.C. O uso da madeira nas Reduções Jesuítico-Guarani do Rio Grande do Sul: 2 - Verga da frontaria da Igreja de São Miguel Arcanjo. Balduinia, Santa Maria, v. 14, p. 29-32, 2008.

SCHULZE-HOFER, C.; MARCHIORI, J.N.C. O uso da madeira nas Reduções Jesuítico-Guarani do Rio Grande do sul. 8 - Mísula do alpendre do Colégio de São Luiz Gonzaga. Balduinia, Santa Maria, v. 19, p. 14-18, 2009a.

SCHULZE-HOFER, C.; MARCHIORI, J.N.C. O uso da madeira nas Reduções Jesuítico-Guarani do Rio Grande do Sul. 4 - Verga da porta da sacristia nova (lado evangelho) da igreja de São Miguel
Arcanjo. Balduinia, v. 15, p. 24-27, 2009 b. SILVA, A.G.C.; DÓRIA, R.C.; LOPES, P.R.; GOES NETO, A. Biodeterioração em construções historicas: estudos de caso da Igreja de Nossa Senhora da Conceição da Praia, Salvador, Bahia. In: Anais. Córdoba, Argentina, VI Congresso Internacional sobre patologia e recuperação de estruturas, 2010. Disponível em: www.cinpar2010.com.ar. Acesso em: janeiro 2017.

TEREZO, R.F. Propriedades mecânicas de madeiras utilizadas em estruturas históricas e contemporâneas estimadas por meio de ultrasom. Dissertação (Mestrado em Engenharia Civil). Universidade Federal de Santa Catarina, Florianópolis, SC, 2004.

WHEELER, E.A. InsideWood - A web resource for hardwood anatomy. IAWA Journal, v. 32, n. 2, p. 199-211, 2011. 